\title{
Perspectivas sociológicas para o estudo dos bens culturais e da atividade cultural \\ Sociological Perspectives For The Study Of The Cultural Goods And The Cultural Activity
}

Douglas Mansur da Silva ${ }^{1}$

\section{Resumo}

O artigo aborda diferentes proposições sociológicas para o estudo dos bens culturais e da atividade cultural, a partir de dois eixos temáticos: 1) as relações entre bens culturais e sociedade e 2) as relações entre cultura e poder.

Palavras-chave: Sociedade, Bens Cultural; Atividade Cultural

\begin{abstract}
The article adduces different sociological proposals for the study of the cultural goods and the cultural activity, from two thematic axles: 1) the relations between cultural goods and society and 2) the relations between culture and power.
\end{abstract}

Keywords: Society, Cultural Goods; Cultural Activity.

1 Doutor - Ciências Sociais - UniFOA

douglas.silva@foa.org.br 


\section{Introdução}

Este artigo tem por objetivo explorar diferentes proposições sociológicas para a análise dos bens culturais e dos campos e movimentos culturais. A questão de trabalho que nos norteia é: de que pontos de vista podem ser estudados os bens culturais e a atividade cultural? ${ }^{1}$ Para tanto, os autores a serem abordados ao longo do texto procuram disponibilizar instrumentais, teóricos e metodológicos que nos permitam pensar a relação e as tensões dialéticas entre arte e sociedade, a partir da modernidade ocidental. Neste sentido, destacam-se, ainda, como elementos importantes, o caráter histórico da experiência artística (e da recepção das obras) e suas relações com a dinâmica dos processos e relações sociais.

Como pano de fundo, neste debate, há, primeiramente, o interesse em reconhecer a validade sociológica para o estudo de temas como arte, literatura, intelectuais e produção científica para a análise das relações e disputas, em torno da constituição da verdade, travadas no interior de campos de conhecimento específicos. Reconhecer a validade sociológica do exame desses assuntos significa dizer que as diversas manifestações de cultura e os meandros desses universos podem ser compreendidos do ponto de vista das Ciências Sociais. Este ponto de vista (ver, por exemplo, Benjamim 1983, Mannheim 1974, Weber 1995, Bourdieu 1996) questiona a genialidade dos autores e a aura de mistério que muitas vezes se atribui às artes; e é preciso lembrar que, apesar do juízo negativo/ normativo de um ou outro sociólogo relativamente à indústria cultural (cf., por exemplo, Adorno 1983), o estudo dos bens culturais a partir de diferentes perspectivas nas Ciências Sociais recusa-se, no seu conjunto, a dividir - ou hierarquizar - a cultura, em cultura de massas, erudita ou popular.

No que diz respeito ao estudo dos bens culturais, os autores que balizam este debate nas Ciências Sociais tendem a enfatizar o vínculo entre bens culturais e sociedade. Mas talvez nem vínculo nem sociedade sejam expressões boas para pensar o assunto. Melhor seria dizer que os bens culturais fazem parte (são instituídos) e dão significado à vida social (são instituintes), em diferentes formas de existência social, localizados no tempo e no espaço. Este artigo ini- cia-se, portanto, a partir deste debate, através da análise das obras de Walter Benjamim, Karl Mannheim, Norbert Elias e Hans Robert Jauss para, num segundo momento, discutir sobre as relações entre cultura e poder, com base na teoria social de autores como, por exemplo, Max Weber, Howard Becker, António Gramsci e Pierre Bourdieu, dentre outros.

\section{Walter Benjamim}

Benjamim (op.cit.) aborda a relação entre a obra de arte e a ordem social em sentido amplo, ao buscar compreender como a experiência artística e os significados da arte são afetados a partir da difusão das técnicas de reprodução seriada dos bens culturais.

A possibilidade de intervenção na própria materialidade da obra traria conseqüências para a sua significação social, retirando sua "aura" de objeto sagrado e voltado à devoção ritual (a arte como culto), e abrindo a possibilidade de se engendrar uma relação mais estreita entre arte e política, por conta do advento de uma nova sociedade - e uma nova ética - onde a intervenção sobre a obra e a constante reprodução do mesmo - conferindo-lhe atualidade permanente - passa a ser tomado como um valor, com efeitos na conduta social.

Como se perguntasse "que novo conceito de arte se pode ter na era das técnicas de reprodução?", Benjamim busca uma conceituação nova sobre a arte. Em seu percurso analítico não autonomiza domínios da arte, mas busca pensar a relação arte-sociedade, e como tais manifestações artísticas seriam expressões de um novo modelo de sociedade, somente possível pela técnica.

Para Benjamim, a uniformização e padronização seguem como característica da modernidade, uma mudança constante de tempo e espaço: como conceituar as mudanças que ocorriam na cultura? Como conceituar a obra de arte agora? Para discutir essas questões, o foco da análise de Benjamim direciona-se para o objeto.

Em princípio, Benjamim problematiza a "perda da autoridade" - a obra de arte não se impõe mais por si só - e esta perda refere-se ao próprio objeto artístico. Ao mudar o objeto, muda-se sua relação com as massas, assim como sua função política. An-

\footnotetext{
${ }^{1}$ Cultura em sentido restrito, isto é, as manifestações artísticas, literárias, ou a produção de obras de pensamento.
} 
tes de tudo, muda-se o modo de sentir e de perceber. Prolonga-se um momento e a percepção própria ao tempo com o qual se relacionava, isto é, até então era a unidade de sua presença no próprio local onde se encontrava que constituía aquilo que se denominava de autenticidade de uma obra.

Com a técnica, o artista dispõe de um novo mecanismo de enquadramento, observação e significação da realidade, sobretudo por sua capacidade de intervenção. Enquanto o curandeiro mantém uma relativa distância - e uma aura - em relação ao doente, o cirurgião intervém em seu modo operatório e é tão somente através da mediação da técnica que pode produzir o efeito desejado. Do mesmo modo, tal diferença se estabelece entre o pintor e o filmador. A imagem produzida por aquele é global, e por este é repartida. Mas só o filmador tem a possibilidade de observar e dar significação a um modo de perceber um dado da realidade que é exclusivo aos membros de uma sociedade que codifique tal aspecto de coisas. Tal só é possível pela técnica, que torna exprimível e verossímil, "porque utiliza instrumentos destinados a penetrar, do modo mais intenso, no coração da realidade".

$\mathrm{O}$ curandeiro tem mana. O cirurgião perde autoridade. Um sacraliza suas práticas e o outro as seculariza. Uma película de cinema pode ser exibida em diferentes tempos e espaços e a audição de uma música pode estar desassociada de seu lugar de execução. Muda-se a relação da obra de arte com seu espectador: Benjamim vislumbra uma "democratização" da obra de arte e uma mudança em sua função, agora menos contemplativa e mais objeto de intervenção. Procura refletir sobre algo novo: o objeto de arte produzido a partir das técnicas, e como tal objeto muda sua relação com o público.

A observação do objeto de modo dessacralizado permite a intervenção sobre sua materialidade e significação, possibilita a transformação, torna-se potencialidade política, mas, significativamente, permite expressar materialmente e esteticamente uma percepção da realidade singular a uma dada sociedade.

\section{Karl Mannheim}

O interesse de Mannheim (op.cit.) não recai tanto sobre processos sociais de larga escala como a modernidade ou a secularização, mas sobre os grupos
- de artistas, intelectuais, etc... - e seus elementos de sociabilidade. Para Mannheim o que une personagens tão distintos é, sobretudo, um saber comum que os congrega e os coloca numa determinada posição social. Tais grupos caracterizam-se mais pelo fato de reunirem indivíduos que têm habitus em comum, em locais compartilhados de sociabilização (como cafés, salões, universidades), do que por constituírem uma classe social, história de vida ou outras posições políticas ou religiosas.

É o saber compartilhado e a prática ou domínio de um saber específico que os congrega, a despeito das diferenças. Há algo que produz as relações entre esses indivíduos e os une - artistas, intelectuais, literatos - qual seja, um conhecimento que compartilham em comum, a cultura e um dado tipo de criação. Tal saber e prática criam a identidade do grupo apesar das lutas internas. Mannheim está mais interessado em pensar a validade das idéias e sobre a relação entre as idéias e o meio social de onde provêm em domínios específicos, do que relacioná-las a transformações provenientes de uma ordem social mais ampla. Ademais, não aborda as disputas e relações de poder no interior desses domínios.

\section{Norbert Elias}

Ao estudar a sociedade de corte, Elias (1987) analisa o que considera um momento específico do processo civilizador, o do surgimento da idéia e de práticas de controle das emoções e dos afetos, tidos socialmente como necessários para a civilidade dos indivíduos. A esse processo segue-se a curialização de certa nobreza francesa, que marcará tanto o surgimento dos jardins quanto de uma vertente do romantismo naquele país.

Um elemento singular a esse processo é a mudança da vida no campo para a corte. A sociedade de corte que então se constitui é analisada por Elias como uma figuração social, no interior da qual se configuram relações hierárquicas e de interdependência entre nobres. Alguns; particularmente aqueles que pertencem às "camadas bifrontes" - por sofrerem pressão de mais de um lado da sociedade - passam a se dedicar às letras, donde emerge a temática, comum ao romantismo, de idealização da vida no campo. Tal idealização torna-se expressão de uma aristocracia 
que não detém poder.

Na obra em questão, Elias define o romantismo a partir de um sentimento de perda, de nobres que decaem em sua posição social e idealizam o passado, ocupando lugares em tal nobreza que condizem com sua atual inserção social.

Para Elias, a base do processo civilizador e da Sociedade de Corte, bem como da sociedade moderna, reside no controle das emoções e dos afetos. O aspecto sociológico está contido no surgimento de "regularidades" e etiquetas socialmente estabelecidas, assim como no controle da natureza, inclusive da "natureza humana". Tal controle ou domínio não é apenas exterior, como nos jardins, mas introjetado.

\section{Digressão}

Há, pois, um elemento de convergência entre esses autores, qual seja, refletir sobre a experiência artística contemporânea dentro de uma dada ordem ou processo social.

O vínculo entre pensamento e sociedade, comum aos três autores, nos faz perguntar em que medida podemos afirmar que dada experiência artística é expressão (ou reflexo) de uma sociedade. Problematizar essa relação direta e necessária entre arte e sociedade, onde a sociologia é o elemento determinante (determinista ou condicionante), é abrir a perspectiva para uma outra modalidade de análise, onde a produção cultural é instituinte. Os três autores pensam a sociedade como instituinte, e não a obra. Ao invertermos o foco, temos a questão: que sociedade é criada a partir (da leitura) dessas obras?

Os bens culturais são instituídos por concepções sociais e instituem algo. Se um primeiro modelo de análise tende a pensar nos grupos, redes de relações ou indivíduos sociais que criam os bens, um segundo modelo pensa em como os bens são lidos, recebidos e instituem o social. A proposição de Jauss é um exemplo de perspectiva de análise que não privilegia a esfera da produção, mas a da recepção. Assim, podemos afirmar que autores tão diversos quanto Benjamim (op. cit.), Mannheim (op.cit.) ou Elias (op.cit.), convergem entre si, por uma questão de ênfase, quando refletem sobre a experiência artística e cultural contemporânea a partir de uma dada ordem ou processo social. Ou seja, tendem a analisá-los muito mais como bens "ins- tituídos".

Mas a relação entre as "obras" e o meio social de onde provém - e que lhe atribui significado e legitimidade - fica incompleta sem se levar em conta o viés instituinte dos "bens culturais". Este ponto de vista nos faz perguntar em que medida podemos nos contentar com a afirmação de que dada experiência artística, por exemplo, é expressão (ou reflexo) de uma sociedade.

\section{Hans Robert Jauss}

Jauss (1993) procura estabelecer os fundamentos de uma concepção de literatura como fenômeno repleto de historicidade. Ao partir de um exame da História e da Teoria da Literatura, o autor discute a possibilidade de se superar as abordagens sincrônica e diacrônica, ao propor que o texto se encontra sempre em aberto para a história, tarefa atribuída ao leitor/intérprete, que o ressignifica, a despeito das especificidades biográficas do autor ou do contexto sistêmico de sua produção. Não se trata de recusar as investidas de pesquisa neste sentido, mas de refutar abordagens estritamente formalistas ou deterministas históricas ou biográficas.

Em seu percurso analítico, Jauss demonstra como ocorreu a oposição entre o modo "historicista" e "cientificista" de se pensar o saber, conseqüência da própria modernidade. $\mathrm{O}$ abandono de uma concepção "historicista" acerca da literatura se deu pela descrença neste modelo, tanto em sua vertente idealista (baseada em uma concepção hegeliana da história) quanto em sua vertente positivista (a partir das concepções deterministas do iluminismo acerca do progresso e, em seguida, do nacionalismo romântico).

A opção por uma abordagem marxista, de um lado, e formalista, de outro, nada mais fez, ao longo de boa parte do século XX, do que repor o dilema já vivenciado pela História da Literatura no XIX, isto é, a oposição entre idealismo esteticista e determinismo extra-literário. Ao "reduzir a arte a um simples reflexo" (pág.15), a orientação marxista recusava-se a compreender o caráter transformador (ou dialético) da literatura e das artes, a de se "abrir a uma percepção nova do mundo, à antecipação de uma realidade nova" (pág.19). Já ao formalismo critica-se a separação ou autonomização excessiva da literatura, destituindo a 
arte de historicidade, de seu vínculo com a vida, em favor de critérios estritamente poéticos e lingüísticos, como se fosse possível a perda do vínculo entre ética e estética. Como explicar então a evolução da literatura como processo? Simples, ora esta questão não se colocava ou, ora, quando feita, restringia-se a uma análise estritamente lingüística, formal-estrutural, o que desprendia o texto da vida e não repunha uma "consciência histórica", mas vinha a reforçar uma concepção estritamente formalista do fenômeno.

A construção de um novo ponto de vista, para Jauss, tem como desafio a capacidade de superação entre essas dicotomias e de lidar com sua historicidade. A proposição de Jauss é a de pensar a experiência do fenômeno literário como uma totalidade; pensa-o como experiência (re)aberta à história, encontrando-se no cerne desta historicidade as possíveis interpretações e releituras das obras, tratando-se de se reivindicar os estudos sobre a recepção das obras, devidamente situados e contextualizados em seus diálogos e efeitos, tanto com relação à história geral quanto com a história específica da literatura.

Deste modo, a superação da oposição entre atemporalidade e temporalidade da obra se dá através da leitura. Une-se a capacidade de despertar (ou de provocar) da obra de arte à experiência de situá-la novamente (e constantemente) no tempo, como ato de ressignificação. Trata-se de uma junção entre fenomenologia e hermenêutica: a "verdade" da obra se faz a partir de sua experiência e de seus efeitos, ou, em outros termos, o sentido do texto exige a tarefa da compreensão, efeito da experiência do diálogo entre leitor e obra. A preocupação com uma "ontologia da obra" deve ser, pois, substituída por questões como o exame de seus efeitos sociais e culturais.

Para Jauss (op.cit.), a obra é percebida a partir de um "horizonte de expectativa", marcado por uma estruturação que permite ao leitor reconhecer os marcadores do texto, tais como a poética de um gênero, a oposição entre ficção e realidade ou a relação implícita com obras conhecidas do universo literário, mas sua possibilidade de objetivação se dá por uma hermenêutica que é possível em decorrência da relação entre literatura e práxis da vida. A literatura, por fim, cria a realidade, uma vez que a compreensão é sempre um processo de "fusão de horizontes" entre obra e leitor. Em linhas gerais, o autor procura abordar o processo de recepção como um sistema semiológico.

\section{Relações entre cultura e poder}

Entretanto, fica uma questão central: como analisar o reconhecimento social dos personagens e das obras? Através da leitura/interpretação apenas ou, de modo complementar, através das inter-relações travadas no interior de um campo do conhecimento? Se as obras, na visão hermenêutica de Jauss, encontram sua força instituinte na leitura, aquele que lê e interpreta tem de buscar legitimar a sua representação do mundo. Está claro que a história não se faz sem agentes e que, portanto, a ação destes não pode ser negligenciada. Por conseguinte, o que importa agora é direcionar o enfoque também para a luta travada pela estruturação dos campos de conhecimento, uma vez que a obra não existe em si, mas seu significado é dado socialmente. Portanto, complementar à discussão sobre as perspectivas sociológicas para o estudo dos "bens culturais" é o debate sobre como se organiza atividade cultural, isto é, quais os elementos orgânicos ou estruturantes das relações nesses campos, os quais possibilitam que, neste jogo, uma interpretação se afirme frente à outra? A luta travada para se legitimar uma dada representação de mundo talvez seja uma das entradas mais promissoras para uma análise do mundo social e, em particular, acerca da totalidade do fenômeno literário, artístico, científico, etc... Esta perspectiva nos faz pensar as artes e a academia sendo um meio social como qualquer outro, apesar de suas especificidades, isto é, dos valores que dão sentido e estruturam as relações e as regras no interior desses campos. Becker (1982), Weber (1964 e 1995), Bourdieu (1991 e 1996) e Elias (s/d), entre outros, balizam este debate.

Howard Becker (op.cit.), interessado em compreender a produção cultural a partir de sua relação com um meio social específico, explora a questão através do conceito de "mundos das artes". Propõe uma análise da arte como atividade coletiva, isto é, como resultado da divisão do trabalho e das relações de cooperação entre um vasto e heterogêneo conjunto de profissionais e atores que, conjuntamente, concorrem para a produção, distribuição e consumo da arte. Esta estratégia analítica, centrada nos modos de organização da atividade cultural, permite ao autor escapar do julgamento estético, a priori, das formas de expres- 
são artística, remetendo para o funcionamento interno dos "mundos das artes" os processos que definem o que é ou não arte.

Definir o que é ou não arte, ou de relevância científica, é parte constitutiva do processo de atribuição dos "bens simbólicos" e do reconhecimento do trabalho de um "autor". Atribuir significado estético ou validade científica a uma obra ou a um especialista envolve não apenas questões formais, mas a dimensão do poder, em particular, a discussão sobre o modo como se estabelece este poder, através de regras, valores, crenças e rituais, processos que medeiam essas relações, de tal forma que uma representação sobre o mundo se torna legítima, isto é, adquire reconhecimento social.

O debate nas ciências sociais sobre a organização da atividade cultural e da produção do conhecimento passa pela discussão sobre os processos de constituição do poder simbólico. Uma síntese das abordagens sobre as relações entre sistemas simbólicos e poder impõe, de imediato, um recorte entre as correntes teóricas que tendem à análise dos signos e sistemas de significação preponderantemente como instrumentos de comunicação (semiologia, estruturalismo) ou conhecimento (Durkheim 1996) e aquelas que tendem a enfocar os sistemas simbólicos como prática social ou instrumentos de dominação.

Embora a "tradição" estruturalista destaque que a "natureza do signo lingüístico" é diacrítica (Saussure 1976) e que, em consonância com tal enfoque, o significado surge da oposição (sendo, por princípio, político), a ênfase metodológica desse tipo de abordagem recai sobre a apreensão da lógica específica das "formas simbólicas", em nível ontológico (Lévi-Strauss 1976) ou sociológico (Durkheim 1996, Radcliffe-Brown 1978).

Direcionado mais especificamente às relações entre sistemas simbólicos e práticas sociais inscreve-se outra "tradição" que remonta, com diferentes abordagens, nas ciências sociais, a Marx e Weber, e ao papel central dos agentes sociais no processo de constituição do simbólico e dos padrões de poder.

Na vertente marxista clássica (ver, por exemplo, Marx 1987), os sistemas simbólicos são abordados privilegiadamente em termos de suas "funções políticas", relacionando-as com os interesses da classe dominante.

Legatário de uma "tradição" marxista, Gra- msci (1978) deu novo fôlego à análise da produção cultural, propondo que as relações entre produção cultural e política não derivariam exclusivamente das relações econômicas, isto é, rompe com a separação (ou determinação) entre infra-estrutura e superestrutura. No tocante à ideologia, Gramsci retira a negatividade marxista do conceito, não importando se esta é falsa ou verdadeira, mas se obedece a dois critérios: 1) eficácia prática; 2) adesão das massas.

Em substituição às noções de infra-estrutura e superestrutura, Gramsci formulou a noção de organicidade, para pensar sobre os elementos que dão amálgama aos aspectos materiais e simbólicos das produções e práticas sociais. Gramsci está mais interessado na racionalidade e na historicidade das idéias. As ideologias orgânicas "colam" superestrutura e infra-estrutura e conduzem o "bloco histórico", com vistas à construção de um processo hegemônico.

Os intelectuais, agentes mediadores dessa transformação, não são vistos por Gramsci em um sentido restrito, como scholars, mas como sujeitos históricos inseridos nas relações sociais, formando "conjuntos orgânicos" que diferenciam suas produções e práticas de outras demais.

Com o mesmo intuito em contribuir para uma abordagem dos sistemas simbólicos como relações de força, Weber (1995) assinala para a constituição dos sistemas simbólicos como instrumentos de imposição ou de legitimação de uma "ordem", contribuindo para a dominação de uma classe sobre a outra (violência simbólica) e para a "domesticação dos dominados". Nesse sentido, as diferentes classes e grupos sociais envolvem-se em uma luta simbólica por representação, em que o que está em jogo é o monopólio da violência simbólica legítima. A crença na legitimidade de algo como, por exemplo, uma obra ou trabalho científico é, de acordo com Weber (1964), elemento central para que se constitua uma relação de dominação. Ao definir a dominação como a probabilidade de ser obedecido, esse autor via na legitimidade uma pretensão à obediência, não uma certeza. A ação de obedecer, por sua vez, pressupõe interesse. Trabalhar a partir da perspectiva de que a crença é um dos pilares das diferentes formas de dominação permite-nos também entrever a possibilidade de se estudar os processos de atribuição de mana a pessoas ou objetos (Mauss \& Hubert 1991).

Já Pierre Bourdieu (1991) apóia-se em Marx, 
Durkheim e Weber, a fim de analisar conjuntamente os sistemas simbólicos como instrumentos de comunicação (conhecimento) e dominação ou, em sua terminologia, como estruturas estruturadas e estruturas estruturantes. De um lado, estruturam as relações através de um modo de construção da realidade, elemento integrador e, na concepção clássica de Durkheim e Radcliffe-Brown, reprodutor de uma ordem social; de outro lado

... é enquanto instrumentos estruturados e estruturantes de comunicação e conhecimento que os 'sistemas simbólicos' cumprem sua função política de instrumentos de imposição ou de legitimação da dominação, que contribuem para assegurar a dominação de uma classe sobre a outra (violência simbólica) dando o reforço de sua própria força às relações de força que as fundamentam e contribuindo assim, segundo a expressão de Weber, para a 'domesticação dos dominados’. (pág.11)

De acordo com Bourdieu (1991), as diferentes classes ou frações de classes envolvem-se numa "luta por representação" para imporem a definição do mundo social, conforme seus interesses. Por conseguinte, luta-se por impor o próprio campo de tomada das posições ideológicas. Tais lutas se travam ora através de conflitos simbólicos cotidianos, ora por meio de "especialistas", produtores simbólicos, onde está em jogo o "monopólio da violência simbólica legítima", noção weberiana apropriada por Bourdieu.

Nesse sentido, complementa o autor

os sistemas ideológicos que os especialistas produzem para a luta pelo monopólio da produção ideológica legítima - e por meio dessa luta -, sendo instrumentos de dominação estruturantes pois que estão estruturados, reproduzem sob forma irreconhecível, por intermédio da homologia entre o campo da produção ideológica e o campo das classes sociais, a estrutura do campo das classes sociais”. (pág.13)

Produzido por um corpo de especialistas, no interior de um campo de circulação relativamente autônomo, os sistemas simbólicos são "duplamente determinados", conforme Bourdieu. De um lado, devem suas especificidades às classes ou frações de classe da qual são expressão, de outro, conformam-se aos interesses específicos de produtores ou corpo de produtores, em concorrência pelo monopólio da "competência” em questão.

Em outro trabalho (Bourdieu, 1996), o autor demonstra de forma sistemática a sua perspectiva sobre a estruturação dos campos artísticos e as regras da produção da arte. Dividida em duas partes, a obra apresenta, em primeiro lugar, uma abordagem histórica sobre a constituição e autonomização do campo literário contemporâneo. $\mathrm{Na}$ segunda parte destacase a retomada de algumas de suas reflexões epistemológicas sobre a legitimidade de um conhecimento sociológico sobre a arte, bem como uma abordagem sistemática sobre as propriedades gerais dos campos da produção cultural.

Norbert Elias (s/d) chama a atenção para que se compreendam as relações humanas como processos que configuram as regras, em padrões de equilíbrio $^{2}$, em que nenhum agente tem poder em si, pois este é relacional. Nesse sentido, em alguns de seus trabalhos (s/d; 1987; 1997), esse autor esteve voltado a uma reflexão sócio-genética sobre os processos de origem e estabelecimento das regras. Tal poder é exercido no interior de uma figuração social, aqui usada para pensar as relações entre os indivíduos, e formada quando existem relações de interdependência. Em Os Estabelecidos e os Outsiders, Elias e Scotson (2000) procuram discutir sobre os mecanismos sociais que permitem que uns indivíduos imponham sua supremacia sobre outros, com destaque para a coesão e coerção interna exercida por um grupo de indivíduos. O aprofundamento teórico sobre essas diferentes perspectivas de análise permite-nos complexificar o poder. Cabe sempre identificar de que poder se trata? Exercido por quem? E como?

\footnotetext{
2 A noção de equilíbrio, em Elias, não remete à idéia de que os agentes detenham as mesmas capacidades de poder, partilhadas entre si, mas a de que se estabelecem "padrões de equilíbrio" através da figuração de certa ordem de poder, não necessariamente igualitária. Encontrar esse padrão, analiticamente, é tarefa de elaboração sociológica.
} 


\section{Conclusões}

Se o reconhecimento da validade sociológica para o estudo dos bens culturais reside, em parte, na consideração que as manifestações culturais podem ser compreendidas por um ponto de vista sociológico, tais proposições têm em comum, nos três primeiros autores analisados, a relação entre arte e sociedade e, por conseguinte, a recusa à "genialidade" dos autores ou a "aura" de mistério atribuída às artes. Em relação a este último aspecto, a "aura de mistério" é questionada por seu valor de análise e não como representação presente no mundo social.

Por outro lado, se há uma experiência coletiva comum, bem como a inserção em um conjunto de relações sociais (tanto de produção quanto de recepção), por que poucos conseguem materializar tal experiência comum? De fato, o indivíduo não é um vazio, destituído de sociedade e o problema é colocá-lo como "gênio". Tal debate nos convida a romper com a dicotomia obra (interna) versus contexto, e mudar o foco da análise do autor para a obra. Há algo na relação arte e sociedade que a torna mais complexa, o lado "eterno" ou "revolucionário" da arte, sua capacidade de ser uma obra aberta à história, de tal modo que a sentença passa a ser a de que os bens cultuais fazem parte (são instituídos) e dão significado (são instituintes) da vida social. O texto de Jauss (op.cit.) chama-nos a atenção para os efeitos de provocação da obra literária, a partir de suas capacidades plásticas. Neste sentido, a narrativa é matéria de recriação. $\mathrm{O}$ efeito produzido na recepção chama a atenção para uma perspectiva pragmática.

Por outro lado, o reconhecimento social de um autor ou obra relaciona-se a universos (ou campos) sociais específicos e às lutas em torno de quem (e como) se constitui a verdade, a legitimidade, a validade do conhecimento, donde os intelectuais, para além de scholars ou especialistas apresentam-se como os personagens capazes de contribuírem na tarefa de interpretação do mundo, através da elaboração dos discursos e das regras que validam a produção e reprodução da cultura.

\section{Referências}

ADORNO, T. W. 1983. “O Fetichismo na Música e a Regressão da Audição” em Textos escolhidos/ Walter Benjamin, Max Horkheimer, Theodor W. Adorno, J. Habermas. São Paulo: Abril Cultural (Os Pensadores), pp. 165-191.

BECKER, Howard. 1982. Art Worlds. Berkeley: University of California.

BENJAMIN, Walter. 1983. “A obra de arte na época de suas técnicas de reprodução” em Textos escolhidos/ Walter Benjamin, Max Horkheimer, Theodor W. Adorno, J. Habermas. São Paulo: Abril Cultural (Os Pensadores), pp. 3-28.

BOURDIEU, Pierre. 1991. O Poder Simbólico. Lisboa: Difel.

1996. Regras da Arte. Gênese e estrutura do campo literário. São Paulo: Cia das Letras.

1997. Razões Práticas. Sobre a teoria da ação. Campinas: Papirus.

2001. Science de la Science et Réflexivité. Paris: Raisons D’Agir Éditions.

ELIAS, Norbert. s/d. O que é Sociologia. Lisboa: Edições 70.

1987. A Sociedade de Corte. Lisboa: Editorial Estampa. 
ELIAS, Norbert.; MARTINS, Hermínio \& WHITLEY, Richard. (eds.) 1982. Scientific Establishments and Hierarquies. Dordrecht: Holland/Boston: USA/London: England: D. Reidel Publishing Company.

ELIAS, Norbert. \& SCOTSON, John L. 2000. Os Estabelecidos e os Outsiders. Sociologia das relações de poder a partir de uma pequena comunidade. Rio de Janeiro: Jorge Zahar Editor.

GRAMSCI, António. 1978. Concepção Dialética da História. Rio de Janeiro: Civilização Brasileira.

JAUSS, Hans Robert. 1993. A literatura como provocação. Lisboa: Ed. Passagens.

MANNHEIM, Karl. 1974. “O problema da intelligentsia: um estudo de seu papel no passado e no presente” em Sociologia da Cultura. São Paulo: Ed Perspectiva/Edusp, pp. 69-139.

MARX, Karl. 1987. A Ideologia Alemã. São Paulo: Hucitec.

MAUSS, Marcel. \& HUBERT, Henri. 1991. “Esquisse d'une théorie génerale de la magie” In: MAUSS, Marcel. Sociologie et Anthropologie. Paris: PUF.

SIMMEL, Georg. 1988. La tragédie de la culture et autres essays. Paris: Éditions Rivages.

WEBER, Max. 1964. Economia y Sociedad. México: Fondo de Cultura Económica. 1995. Os Fundamentos racionais e sociológicos da música. São Paulo: Edusp.

\section{Informações bibliográficas:}

Conforme a NBR 6023:2002 da Associação Brasileira de Normas Técnicas (ABNT), este texto científico publicado em periódico eletrônico deve ser citado da seguinte forma:

SILVA, D. M.. Perspectivas sociológicas para o estudo dos bens culturais e da atividade cultural. Cadernos UniFOA, Volta Redonda, ano II, n. 4, agosto. 2007. Disponível em: <http://www.unifoa.edu.br/pesquisa/caderno/edicao/04/72.pdf> 